\title{
RESPONSE OF UHPFRC COLUMNS SUBMITTED TO COMBINED AXIAL AND ALTERNATE FLEXURAL LOADS
}

\author{
C.Eng. Pierre Marchand ${ }^{1}$ \\ Ph.D., Eng. Florent Baby ${ }^{2}$ \\ Ph.D., Eng. Aghiad Khadour ${ }^{3}$ \\ C.Eng. Philippe Rivillon ${ }^{4}$ \\ Jean-Claude Renaud ${ }^{5}$ \\ Lénaïc Baron ${ }^{6}$ \\ Eng. Grégory Généreux ${ }^{7}$ \\ Eng. Jean-Paul Deveaud ${ }^{8}$ \\ C.Eng. Alain Simon ${ }^{9}$ \\ Ph.D., P.Eng. François Toutlemonde ${ }^{10}$
}

\section{Abstract}

This paper deals with the experimental determination of ductility of ultra-high-performance fiber-reinforced concrete (UHPFRC) columns with longitudinal passive reinforcement, tested under combined axial and alternate flexural load. The influence of axial load has been stud-

\footnotetext{
${ }^{1}$ Université Paris-Est - IFSTTAR, 77447 Marne la Vallée Cedex 2, France. E-mail: pierre.marchand@ifsttar.fr

${ }^{2}$ Direction de l'environnemnent, de l'aménagement et du logement, La Réunion, France. E-mail: florent.baby@developpement-durable.gouv.fr

${ }^{3}$ Université Paris-Est - IFSTTAR, 77447 Marne la Vallée Cedex 2, France. E-mail: aghiad.khadour@ifsttar.fr

${ }^{4}$ Centre Scientifique et Technique du Bâtiment, 77447 Marne la Vallée Cedex, France. E-mail: philippe.rivillon@cstb.fr

${ }^{5}$ Université Paris-Est - IFSTTAR, 77447 Marne la Vallée Cedex 2, France. E-mail: jeanclaude.renaud@ifsttar.fr

${ }^{6}$ Université Paris-Est - IFSTTAR, 77447 Marne la Vallée Cedex 2, France. E-mail: lenaic.baron@ifsttar.fr

${ }^{7}$ CEREMA-DTecITM-CTOA-DGOI, 110 rue de Paris, 77171 Sourdun, France. E-mail: gregory.genereux@cerema.fr

${ }^{8}$ CEREMA-DTerCE/DLL/OASMD/DOA, 25 Avenue François Mitterrand, 69274 Bron, France. E-mail: jean-paul.deveaud@cerema.fr

${ }^{9}$ Eiffage BIEP, 78140 Vélizy Villacoublay, France. E-mail: alain.simon@eiffage.com

${ }^{10}$ Université Paris-Est - IFSTTAR, 77447 Marne la Vallée Cedex 2, France. E-mail: francois.toutlemonde@ifsttar.fr
} 
ied, as well as the presence or not of a reduced shear reinforcement. One companion column made of ordinary concrete and with a high shear reinforcement ratio has also been tested for comparison. The ductility has been assessed with energy dissipation and ductility coefficient calculations. In addition, the maximum bending moment has been compared with theoretical calculation, using the material characteristics determined from characterization tests. The paper concludes that UHPFRC columns with a longitudinal reinforcement which have not been specifically designed for seismic resistance do display a ductility coefficient higher than 2 and a noticeable ability to protect the rebars from buckling but a rather high decrease of bending moment under the succession of series of alternate flexural load cycles.

Keywords: Ultra High Performance Fibre Reinforced Concrete (UHPFRC), Ultra-High Performance Concrete (UHPC), Column, Seismic behaviour, Ductility

\section{INTRODUCTION}

Ultra-High Performance Fiber Reinforced Concrete (UHPFRC) is a range of cement based composite materials with remarkable mechanical properties for both compressive and tensile behaviour and with excellent durability properties (AFGC 2013), (Behloul 1996), (Chanvillard and Rigaud 2003), (Graybeal 2011), (Naaman and Reinhardt 1996), (Richard and Cheyrezy 1995), (Spasojević 2008), (Walraven 2009)). These outstanding properties are used to produce light and durable structures, bringing new architectural possibilities ((Toutlemonde and Resplendino 2011)).

Many articles or reference manuals about ductility of reinforced concrete structures can be found, such as (FHWA 2014) or (CEREMA 2015). It is also possible to find a few references about the ductility of columns using UHPFRC. (Massicotte and Boucher-Proulx 2011) have shown that UHPFRC can be used with efficiency to retrofit existing RC columns. In this paper, a thin UHPFRC jacket was cast at the junction of footing and column which led to a significant increase in ductility of the column submitted to flexural loading. An equivalent idea was tested in (Sogabe et al. 2008) but with several precast UHPFRC segments around the reinforcement of an RC column. The specimens were tested under combined axial and 
alternate flexural loading and display a very good ductility. The precast UHPFRC elements have enabled to keep the concrete cover and prevented the reinforcement from buckling. The same concept was tested by (Ichikawa et al. 2016): two specimens consisting of an ordinary reinforced concrete core surrounded by precast UHPFRC hollow segments and a specimen consisting of only the precast UHPFRC segments were tested under combined axial and orbital bilateral cyclic loading and showed good results in terms of ductility and residual deformations. (Palacios et al. 2015) have tested two reinforced concrete columns with $711 \times 711 \mathrm{~mm}^{2}$ square cross-section, $2.69 \mathrm{~m}$ tall, with a high density of longitudinal rebars and shear reinforcement. The first column was made of ordinary concrete (OC) only while UHPFRC replaced the ordinary concrete on the first 1,01 $m$ part of the column adjacent to the footing. Both specimens were subjected to combined axial (about $10 \mathrm{MPa}$ ) and alternate flexural load. The specimen with the UHPFRC showed a better behaviour in terms of maximum bending moment and ductility. (Tazarv and Saiid Saiidi 2014) have shown that UHPFRC can be used to fill ducts containing rebars linking precast elements such as a cap-beam with a column or a column with a footing. This enables reducing the embedment length making it possible to reduce the depth of the cap-beam or footing. Because the anchor length of rebars in UHPFRC is very short, the rebars have been debonded over a small length at the junction between the two precast elements to increase the ductility. This connecting process has been tested and the results have shown that a ductility suitable for high seismic zones can be reached. Concerning the behaviour of non reinforced UHPFRC submitted to alternate flexural loading, (Frettlöhr et al. 2012) have shown that prisms submitted to repeated load cycles can be subjected to 250 cycles for a load corresponding to twice the elastic limit. It shows that the ductility decreases by $25 \%$ in the case of alternate cyclic loading compared with repeated loading and that the stiffness decreases quickly after crack localization.

In this paper, the ductility of thin UHPFRC columns with longitudinal reinforcement and the presence or not of low shear reinforcement has been investigated. The columns 
have been submitted to both axial compression and alternate transverse loading resulting in an alternate bending moment. The main idea is to check if UHPFRC columns with no transverse reinforcement or with reduced transverse reinforcement (as results from current non-seismic design according to (AFNOR 2016a) in low seismic areas) can behave properly under low seismic action.

UHPFRC columns and one single column made of ordinary reinforced concrete designed according to Eurocode 8 ((AFNOR 2005b)) principles for seismic resistance have been fabricated and tested. Experimental results are detailed, and the ductility of such structures is discussed.

\section{DESCRIPTION OF THE EXPERIMENTAL PROGRAM}

\section{Tested specimens}

Nine UHPFRC specimens have been fabricated, using two types of mixes, including or not polypropylene fibers (such polypropylene fibers are generally used for spalling prevention in case of fire). These specimens consist in a 1,5 $\mathrm{m}$ long column shaft anchored in a 1,5 $\mathrm{m}$ footing. Both parts were cast at the same time, leading to a material continuity (in terms of fibers) at the junction of the footing and the column shaft. Shear reinforcement has been provided in some of the specimens in the vicinity of the junction.

Figure 1 details the geometry of the UHPFRC columns and the ribbed reinforcing bars layout, and shows some pictures of the formworks and rebars before concrete casting.

The two types of UHPFRC mixes that were used are commercially available in Europe ((Dutalloir et al. 1998), (Toutlemonde et al. 2013)). UHPFRC1 comprises polypropylene fibers in addition to $2.5 \%$ vol. steel fibers, whereas UHPFRC2 comprises only steel fibers. Table 1 provides details about these UHPFRC mixes and about their mechanical characteristics, determined according to (AFGC 2013) and (AFNOR 2016b). Tensile properties have been determined through 3- and 4-point bending tests on prisms and inverse analysis.

One companion ordinary concrete (OC) specimen has also been fabricated, with an enlarged column and a high shear and longitudinal reinforcement ratio in the column. It was 

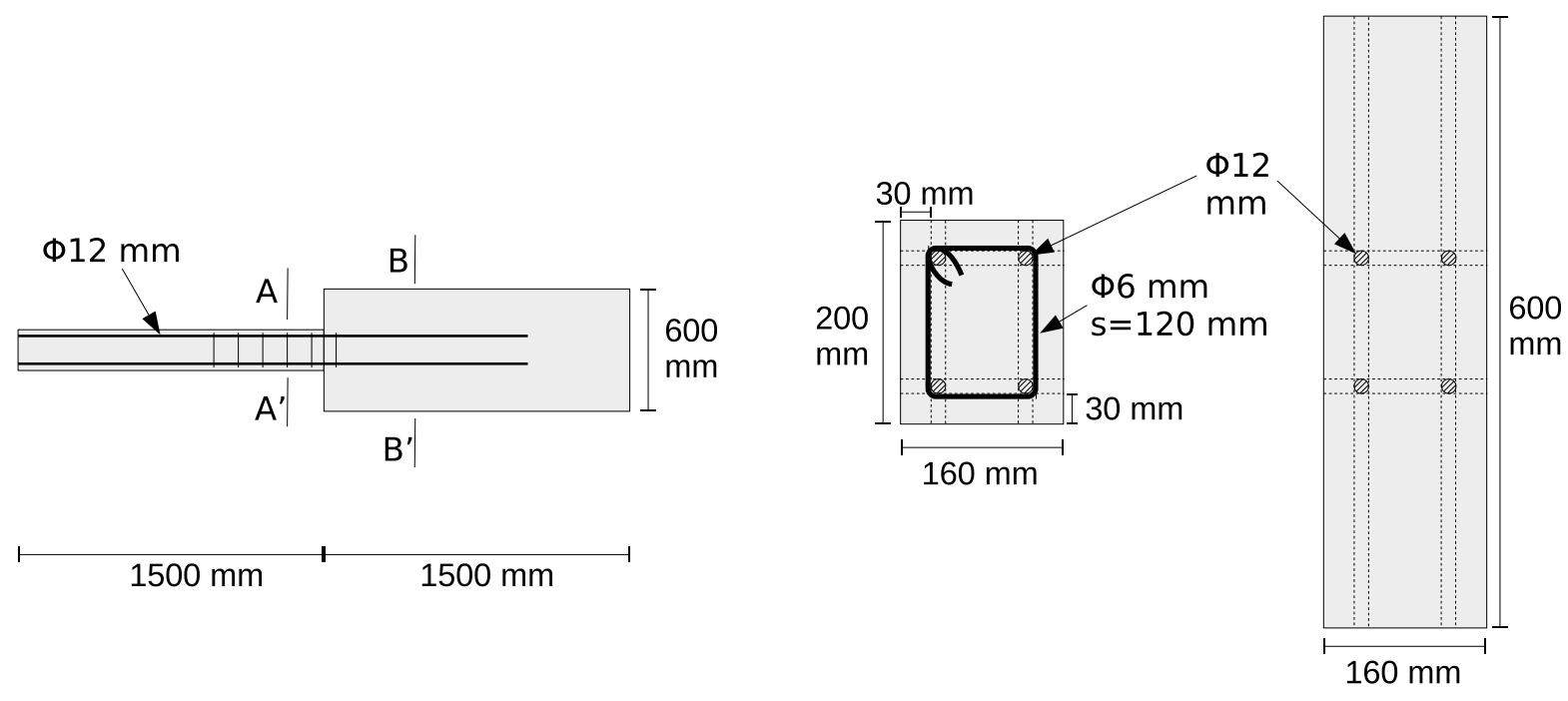

Section A-A'

Section B-B'
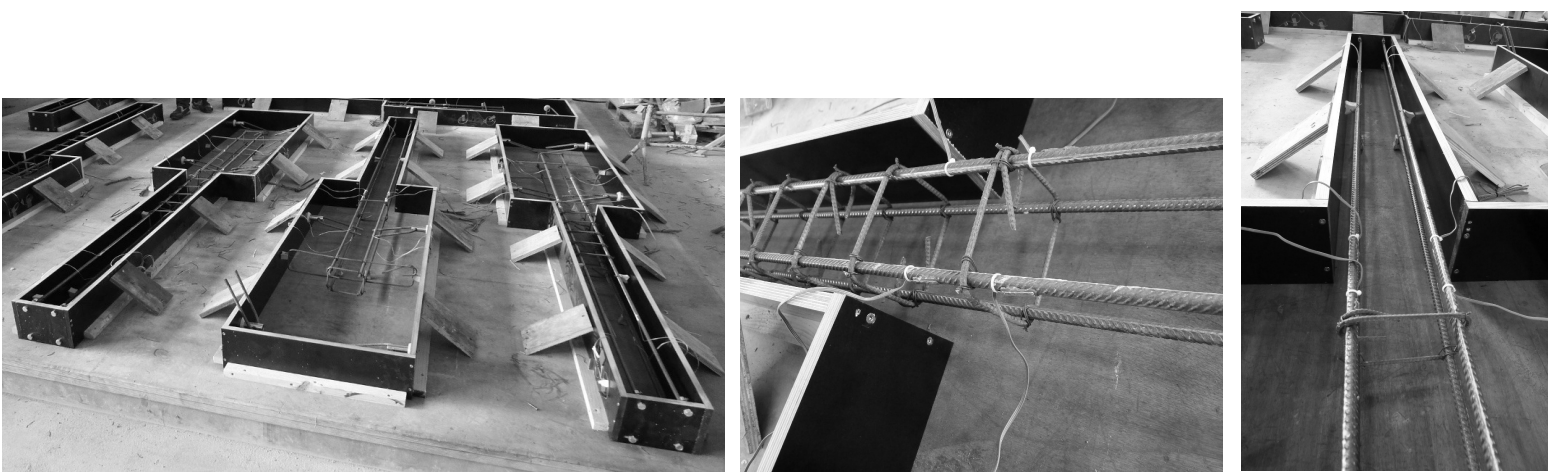

Figure 1. UHPFRC specimens: geometry and pictures of formwork and reinforcement before casting

designed to take the same axial load as the UHPFRC specimens and following Eurocode 8 (AFNOR 2005b) design rules. It subsequently has a cross-section multiplied by 4.2 .

Figure 2 shows the ordinary concrete specimen geometry and reinforcement layout and exhibits some pictures of the formwork and the reinforcement before concrete casting.

After casting, a curing compound conforming to NF P 18-370 (AFNOR 2013) has been applied, and the specimens have been covered with a thin plastic sheet to protect them from dessication. No thermal or moisture treatments were performed.

The ordinary concrete mix proportions and associated material characteristics are given in Table 1. 



Figure 2. OC specimen: geometry and pictures of formwork and reinforcement before casting

Steel reinforcing bars used in the specimens are typically available from the French market (characteristic yield strength, $f_{y k}=500 \mathrm{MPa}$ ). Table 2 gives the characteristics of the longitudinal rebars. These characteristics were determined by tests according to NF EN 15630-1 (AFNOR 2010). If we compare these rebars characteristics to those used in high seismicity regions, we can note that the ultimate strain is significantly lower while the yield stress is closer to the ultimate. This tends to reduce ductility because yielding occurs later while bar rupture occurs earlier. All the rebars placed in the UHPFRC specimens to provide longitudinal reinforcement were grooved to introduce a fiber optic sensor. This sensor enables to measure the strain along the rebars with a spatial resolution of about $1 \mathrm{~mm}$, as described 
in (Marchand et al. 2015). Six $16 \mathrm{~mm}$ rebars placed in the OC specimen were grooved and equipped with a fiber optic sensor (rebars at the upper chord and lower chord).

Table 3 shows which specimens were tested, their main characteristics and the corresponding testing procedure applied. Four UHPFRC specimens (three with shear reinforcement, one without) and the $\mathrm{OC}$ specimen were tested with a high axial load (1.12 $\mathrm{MN}$ ). Five UHPFRC specimens (four with shear reinforcement, one without) have been tested with a reduced axial load $(0.64 M N)$. For each axial load, one test has been done with a repeated loading protocol while the other tests were performed with an alternate loading protocol as described in the following section.

The value of the axial force applied on the UHPFRC columns was chosen equal to either $1120 k N$ or $640 k N$ corresponding respectively to a compressive stress $\sigma_{c}$ of $35 \mathrm{MPa}\left(\sigma_{c} / f_{c} \approx\right.$ $0.159)$ or $20 \mathrm{MPa}\left(\sigma_{c} / f_{c} \approx 0.091\right)$. The OC specimen was tested with an axial force of $1120 k N$ corresponding to $8.3 \mathrm{MPa}\left(\sigma_{c} / f_{c} \approx 0.191\right)$.

Remark: in this paper, concrete stress is taken as positive for compression and negative for tension.

\section{Test setup and test procedure}

The test setup is described in Figures $3 \mathrm{a}, 3 \mathrm{~b}, 3 \mathrm{c}$ and $3 \mathrm{~d}$. It enables :

- clamping the specimen footing on the strong floor through the use of prestressing bars;

- applying an axial force on the column, with jacks placed behind the footing and with prestressing bars placed on each side of the column;

- applying a vertical alternate force on the extremity of the column (1.2m of the junction between the footing and the column) with a vertical jack with sufficient stroke and a special designed steel piece that transfers the force on the column but restrains neither the rotation nor the axial displacement.

The vertical jack applied an initial upward force to compensate for the column self-weight 
Table 1. Characteristics of UHPFRC and concrete mixes

\begin{tabular}{|c|c|c|c|}
\hline $\begin{array}{l}\text { Components or } \\
\text { characteristics }\end{array}$ & UHPFRC 1 & UHPFRC 2 & $\mathrm{OC}$ \\
\hline \multicolumn{4}{|c|}{ Mix } \\
\hline $\begin{array}{l}\text { Cement \& } \\
\text { aggregates }\end{array}$ & premix $2299 \mathrm{~kg} / \mathrm{m}^{3}$ & premix $2295 \mathrm{~kg} / \mathrm{m}^{3}$ & $\begin{array}{l}\text { cement: } 415 \mathrm{~kg} / \mathrm{m}^{3} \\
\text { aggreg: } 1815 \mathrm{~kg} / \mathrm{m}^{3}\end{array}$ \\
\hline Superplasticizer & $38 \mathrm{~kg} / \mathrm{m}^{3}$ & $50 \mathrm{~kg} / \mathrm{m}^{3}$ & $3.6 \mathrm{~kg} / \mathrm{m}^{3}$ \\
\hline $\begin{array}{l}\text { Straight steel } \\
\text { fibers }\end{array}$ & $\begin{array}{l}195 \mathrm{~kg} / \mathrm{m}^{3} \\
(2.5 \% \text { in volume }) \\
L_{f}=20 \mathrm{~mm} \\
\phi_{f}=0.3 \mathrm{~mm}\end{array}$ & $\begin{array}{l}195 \mathrm{~kg} / \mathrm{m}^{3} \\
(2.5 \% \text { in volume }) \\
L_{f}=20 \mathrm{~mm} \\
\phi_{f}=0.3 \mathrm{~mm}\end{array}$ & - \\
\hline $\begin{array}{l}\text { Polypropylene } \\
\text { fibers }\end{array}$ & $\begin{array}{l}1.5 \mathrm{~kg} / \mathrm{m}^{3} \\
L_{f}=12 \mathrm{~mm} \\
\phi_{f}=18 \mu \mathrm{m}\end{array}$ & - & - \\
\hline Water & $203 \mathrm{~kg} / \mathrm{m}^{3}$ & $190 \mathrm{~kg} / \mathrm{m}^{3}$ & $225 \mathrm{~kg} / \mathrm{m}^{3}$ \\
\hline Curing regime & \multicolumn{3}{|c|}{ laboratory conditions } \\
\hline $\begin{array}{l}\text { Dynamic slump } \\
\text { flow (DIN cone } \\
\text { test after mixing) }\end{array}$ & {$[510,610] \mathrm{mm}$} & $660 \mathrm{~mm}$ & - \\
\hline $\begin{array}{l}\text { Slump with } \\
\text { Abrams cone }\end{array}$ & - & - & $130 \mathrm{~mm}$ \\
\hline \multicolumn{4}{|c|}{ Mechanical characteristics at the age of test (mean values) } \\
\hline $\begin{array}{l}\text { Compressive } \\
\text { strength }^{a} \\
\text { mean value } f_{c m}\end{array}$ & $220.2 \mathrm{MPa}$ & $222.5 \mathrm{MPa}$ & $43.5 \mathrm{MPa}$ \\
\hline $\begin{array}{l}\text { Tensile strength } \\
\mathbf{f}_{\mathbf{c t m}, \mathbf{e l}} \\
\boldsymbol{\sigma}(\mathbf{w}=\mathbf{0 . 3 m m})^{c} \\
\boldsymbol{\sigma}(\mathbf{w}=\mathbf{1} \mathbf{m m})^{c} \\
\mathbf{f}_{\mathbf{c t m}}{ }^{d}\end{array}$ & $\begin{array}{l}14.0 \mathrm{MPa} \\
14.3 \mathrm{MPa} \\
12.9 \mathrm{MPa} \\
-\end{array}$ & $\begin{array}{l}\text { 14.4 MPa } \\
15.3 \mathrm{MPa} \\
14.3 \mathrm{MPa} \\
-\end{array}$ & $\begin{array}{l}- \\
- \\
- \\
3,0 \mathrm{MPa}\end{array}$ \\
\hline Young's modulus & $62.5 \mathrm{GPa}$ & $62.1 \mathrm{GPa}$ & $28.8 \mathrm{GPa}$ \\
\hline Poisson's ratio & 0.22 & not measured & not measured \\
\hline
\end{tabular}

${ }^{a}$ measured on $110 \times 220 \mathrm{~mm}$ cylinders for UHPFRC and on $160 \times 320 \mathrm{~mm}$ cylinders for OC

${ }^{b}$ measured through 4 point bending tests on $100 \times 100 \times 400 \mathrm{~mm}$ prisms, according to (AFNOR 2016b)

${ }^{c}$ measured through 3 point bending tests on $100 \times 100 \times 400 \mathrm{~mm}$ prisms and inverse analysis, according to (AFNOR 2016b)

${ }^{d}$ determined by splitting test 


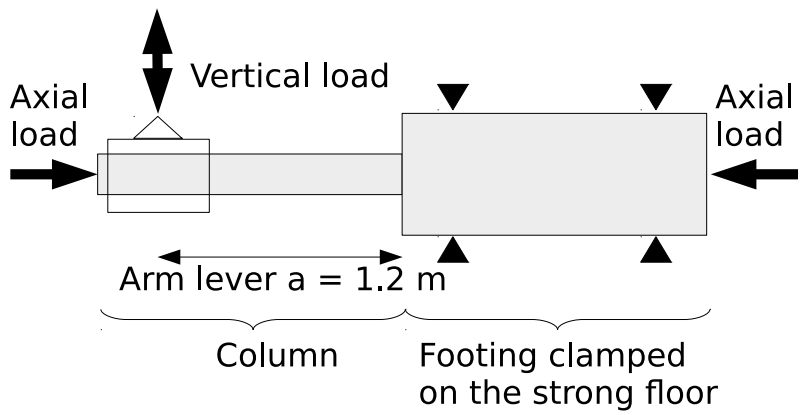

(a)

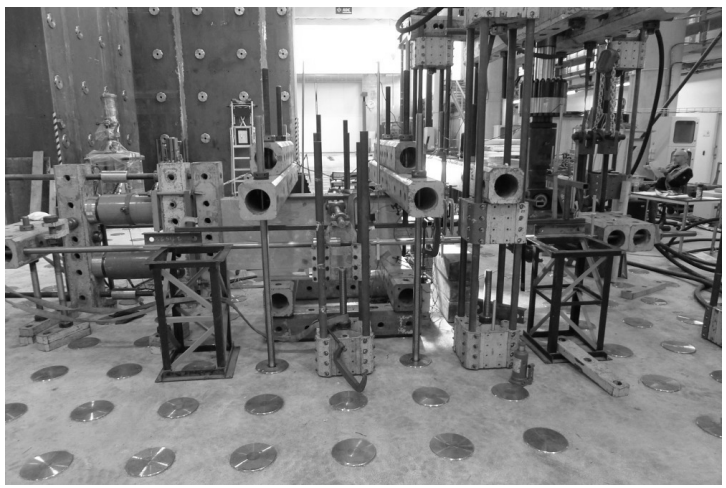

(c)

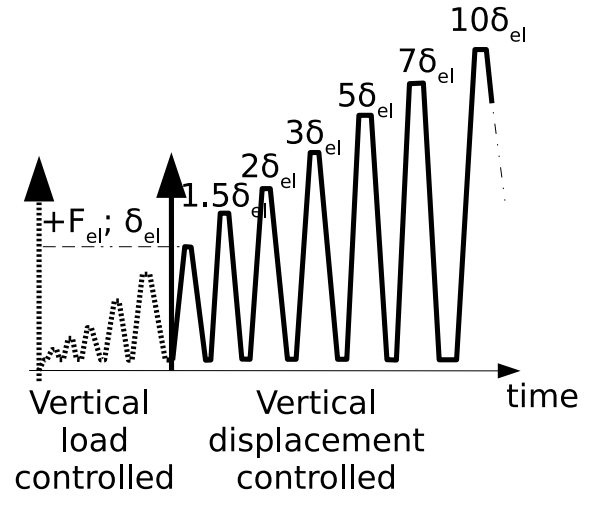

(e)

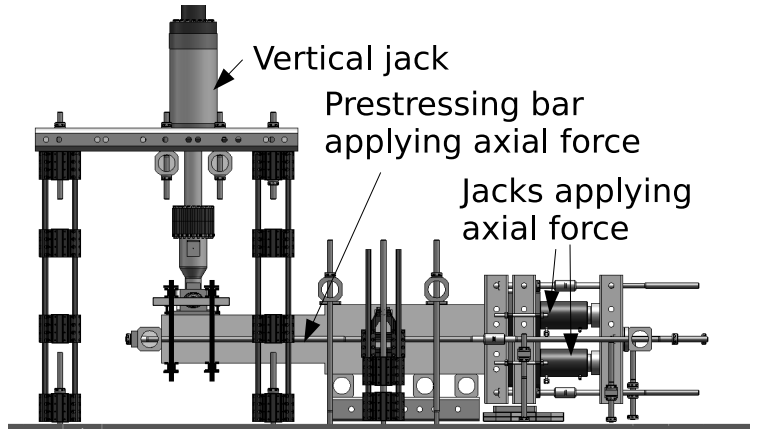

(b)

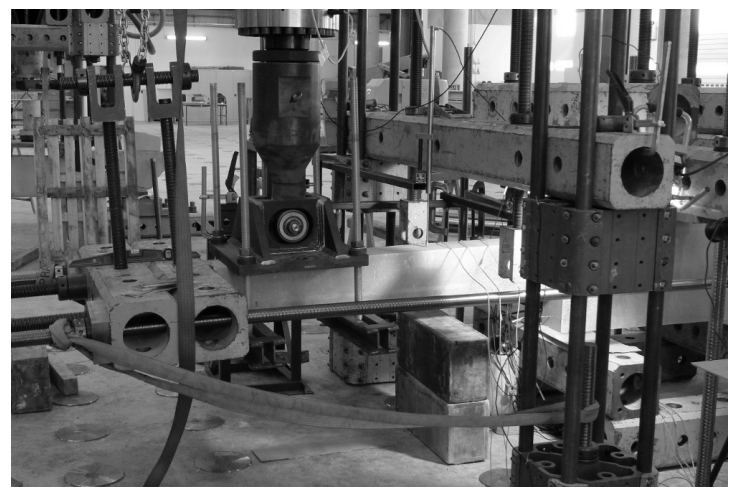

(d)

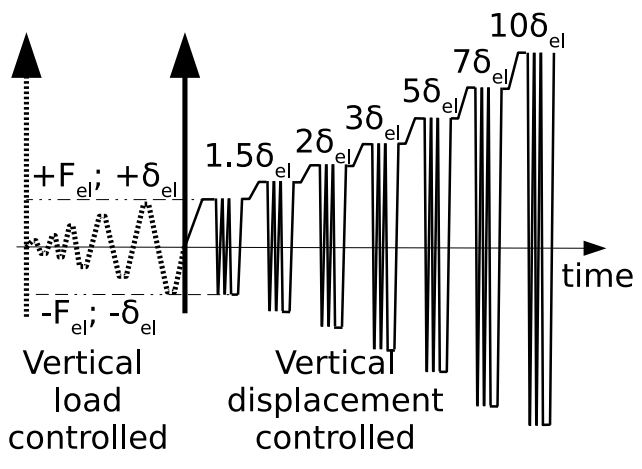

(f)

Figure 3. Experiments on the columns: (a) test principle; (b) scheme of the test setup; (c) picture of the test setup; (d) picture of the test setup, focus on the extremity of the column; (e) repeated load protocol ; (f) alternate load protocol 
Table 2. Steel rebars characteristics

\begin{tabular}{|c|c|c|c|c|}
\hline \multirow[t]{2}{*}{ Characteristics } & \multicolumn{2}{|c|}{$12 \mathrm{~mm}$ diameter } & \multicolumn{2}{|c|}{$16 \mathrm{~mm}$ diameter } \\
\hline & Not grooved & Grooved & Not grooved & Grooved \\
\hline Young's modulus (GPa) & 188.4 & 186.9 & 190.5 & \\
\hline Yield strength fy (MPa) & & & 518. & \\
\hline Proof Stress at $0.2 \%(\mathrm{MPa})$ & 532.1 & 516.0 & & \\
\hline Ultimate stress (MPa) & 590.5 & 577.4 & 624. & \\
\hline Ultimate strain (\%) & 4.37 & 6.37 & 8.8 & \\
\hline Type of steel & \multicolumn{2}{|c|}{ cold worked } & \multicolumn{2}{|c|}{ hot rolled } \\
\hline
\end{tabular}

Table 3. Tested specimens

\begin{tabular}{cccccc}
\hline Specimen & Material & Long reinf & Shear reinf & Ax. load & Protocol \\
\hline U1-S-HL-R & UHPFRC 1 & $4 \phi 12 \mathrm{~mm}$ & $\phi 6 \mathrm{~mm}, \mathrm{~s}=12 \mathrm{~cm}$ & $1.12 M N^{a}$ & repeated \\
U1-S-HL-A & UHPFRC 1 & $4 \phi 12 \mathrm{~mm}$ & $\phi 6 \mathrm{~mm}, \mathrm{~s}=12 \mathrm{~cm}$ & $1.12 M N^{a}$ & alternate \\
U2-S-HL-A & UHPFRC 2 & $4 \phi 12 \mathrm{~mm}$ & $\phi 6 \mathrm{~mm}, \mathrm{~s}=12 \mathrm{~cm}$ & $1.12 M N^{b}$ & alternate \\
U1-NS-HL-A & UHPFRC 1 & $4 \phi 12 \mathrm{~mm}$ & no & $1.12 M N^{a}$ & alternate \\
U1-S-RL-R & UHPFRC 1 & $4 \phi 12 \mathrm{~mm}$ & $\phi 6 \mathrm{~mm}, \mathrm{~s}=12 \mathrm{~cm}$ & $0.64 M N^{c}$ & repeated \\
U1-S-RL-A-a & UHPFRC 1 & $4 \phi 12 \mathrm{~mm}$ & $\phi 6 \mathrm{~mm}, \mathrm{~s}=12 \mathrm{~cm}$ & $0.64 M N^{c}$ & alternate \\
U1-S-RL-A-b & UHPFRC 1 & $4 \phi 12 \mathrm{~mm}$ & $\phi 6 \mathrm{~mm}, \mathrm{~s}=12 \mathrm{~cm}$ & $0.64 M N^{c}$ & alternate \\
U2-S-RL-A & UHPFRC 2 & $4 \phi 12 \mathrm{~mm}$ & $\phi 6 \mathrm{~mm}, \mathrm{~s}=12 \mathrm{~cm}$ & $0.64 M N^{d}$ & alternate \\
U2-NS-RL-A & UHPFRC 2 & $4 \phi 12 \mathrm{~mm}$ & no & $0.64 M N^{d}$ & alternate \\
O-S-HL-A & OC & $8 \phi 16 \mathrm{~mm}$ & $2 \phi 10 \mathrm{~mm}, \mathrm{~s}=9 \mathrm{~cm}$ & $1.12 M N^{e}$ & alternate \\
\hline
\end{tabular}

${ }^{a}$ compressive stress $\sigma_{c}=35 \mathrm{MPa}$ and $\sigma_{c} / f_{c}=0.159$

${ }^{b}$ compressive stress $\sigma_{c}=35 \mathrm{MPa}$ and $\sigma_{c} / f_{c}=0.157$

${ }^{c}$ compressive stress $\sigma_{c}=20 \mathrm{MPa}$ and $\sigma_{c} / f_{c}=0.091$

${ }^{d}$ compressive stress $\sigma_{c}=20 \mathrm{MPa}$ and $\sigma_{c} / f_{c}=0.090$

${ }^{e}$ compressive stress $\sigma_{c}=8.3 \mathrm{MPa}$ and $\sigma_{c} / f_{c}=0.191$

(the aim was to cancel the bending moment due to the column self-weight at the junction between the footing and the column).

When the axial force was progressively increased to reach its target value, the vertical jack applied a constant displacement and its load cell was used to check that the axial force possible excentricity was very limited (a perfect axial force theoretically generates no reaction force in the vertical jack). If the variation of load applied by the vertical jack was considered too high, the axial force was released and the position of the point at the extremity of the column where the axial load was applied was modified.

Once the requested axial force was reached, the vertical jack applied a vertical load to 
generate a bending moment in the colunm. This load was either applied repeatedly (force downward only) or alternatively (force successively downward and upward) as described in Figures 3e and 3f respectively. In a first phase, the jack applied an increasing load in successive steps up to the calculated elastic force $F_{e l}$.

The values of $F_{e l}$ and the different steps in the first phase are:

- for UHPFRC specimens tested with high axial load $N=1120 k N: F_{e l}=40 k N$, and the load step values before reaching $F_{e l}$ are $F_{1}=5 k N, F_{2}=10 k N, F_{3}=20 k N$, $F_{4}=30 k N$;

- for UHPFRC specimens tested with reduced axial load $N=640 \mathrm{kN}: F_{e l}=25 \mathrm{kN}$, and the load step values before reaching $F_{e l}$ are $F_{1}=5 k N, F_{2}=10 k N, F_{3}=15 k N$, $F_{4}=20 k N$;

- for the OC specimen tested with axial load $N=1120 \mathrm{kN}: F_{e l}=60 \mathrm{kN}$, and the load step values before reaching $F_{e l}$ are $F_{1}=20 \mathrm{kN}$ and $F_{2}=40 \mathrm{kN}$.

Once the calculated elastic force $F_{e l}$ was reached, the corresponding displacement $\delta_{e l}$ was noted and then the jack applied increasing displacements up to $1.5 \delta_{e l}, 2 \delta_{e l}, 3 \delta_{e l}, 5 \delta_{e l}, 7 \delta_{e l}$, and $10 \delta_{e l}$ either in single steps for the repeated protocol, or in series of 3 cycles for each displacement value for the alternate protocol.

\section{RESULTS}

\section{Correction due to axial load excentricity}

Due to the deformation of the column during the test, the prestressing bars applying axial load were no longer aligned with the axis of the section at the junction between the footing and the column where the bending moment is maximal (see Figure 4a). Hence, the prestressing bars apply a bending moment on the column. The total bending moment at the junction between the footing and the column is equal to :

$$
M=F_{\text {vertical }} \times a+e \times F_{\text {axial }}
$$




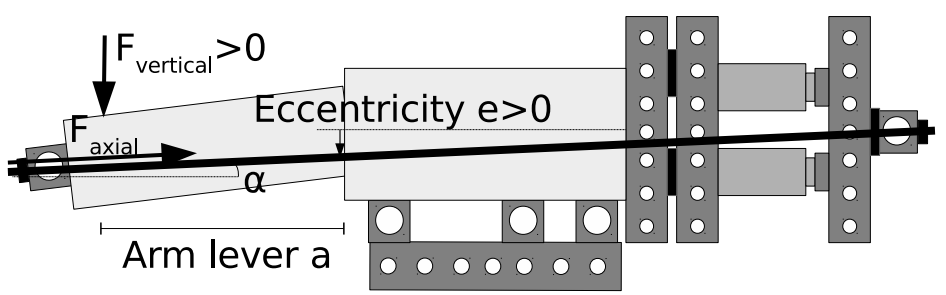

(a)

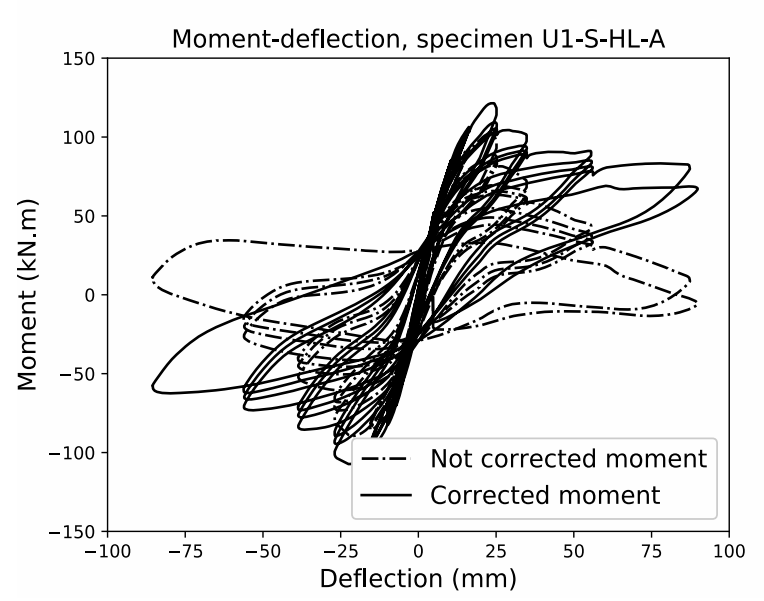

(b)

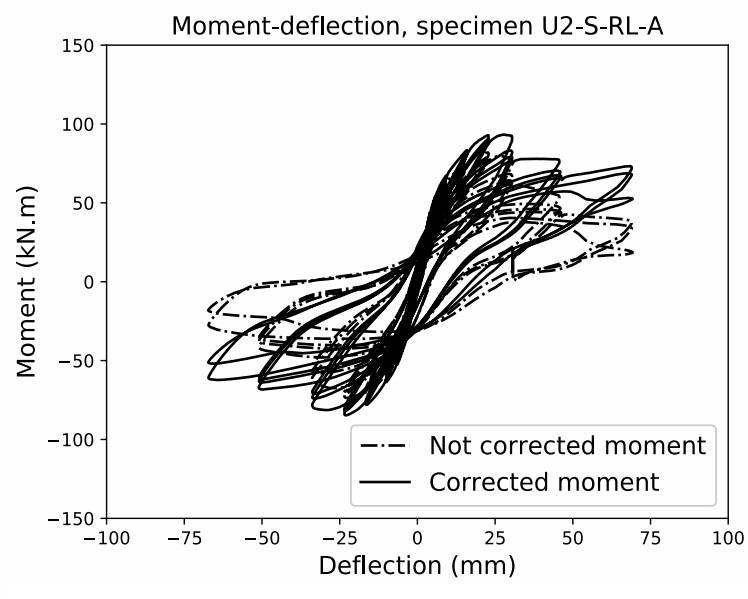

(c)

Figure 4. Geometrical artefacts: (a) scheme showing prestressing bars eccentricity at the junction between the footing and the column; (b) and (c) bending moment curve with (and without) correction due to prestressing bars excentricity for U1-S-HL-A and U2-S-RL-A

The cosine term in front of $e \times F_{\text {axial }}$ is omitted here because the inclination angle of prestressing bars was small. Conversely, the bending moment generated by the axial force excentricity is not negligible compared to the bending moment generated by the vertical load (see Figures 4b and 4c). To precisely account for it, the excentricity of the prestressing bars at the junction between the footing and the column has been measured directly with two displacement sensors.

In the next parts of the paper, only the corrected bending moment is considered.

Remark: the deflection considered in this paper was the column vertical displacement at a distance of $1.2 \mathrm{~m}$ of the junction between footing and shaft of the column, which corresponds to the displacement applied by the vertical jack. 


\section{Comparison of envelope bending moment-deflection curves}

In order to compare properly the bending moment-deflection curves for the different tested specimens, the envelope curves have been plotted using only the points corresponding to the maximum deflection of every cycle. Figures $5 \mathrm{a}, 5 \mathrm{~b}$ and $5 \mathrm{c}$ show the envelope curves with the associated whole curves on three UHPFRC specimens. The peak observed on Figure $5 \mathrm{c}$ is not realistic because it was caused by a chain (forgotten unintentionnally) preventing the column from going downward. This peak was not taken into account in the next parts of this document. Figure 5d shows the envelope curve and the whole bending moment curve of the ordinary concrete specimen. The y-scale has been enlarged because this specimen shows a higher capacity in terms of bending moment.

Figures 5e and $5 \mathrm{f}$ show the envelope curves of UHPFRC specimens tested with a high axial load $(N=1120 k N)$ and a reduced axial load $(N=640 k N)$. It was observed that the ductility was higher in the case of repeated protocol than in the case of alternate protocol (the bending moment decreases more slowly). It was also noted that the presence of shear reinforcement in the UHPFRC specimens has a slight beneficial effect, especially with a high axial load.

\section{Failure mechanisms and comparison of the maximum bending moments with the theoretical values}

Test results

Table 4 shows the maximum bending moments (minimum and maximum values) for alternate protocol tests. A comparison with calculated values and details of the failure mechanism are given. The distance $d_{\text {fail }}$ between the final crack or the compressive failure zone and the junction between the footing and the column shaft is also given in this table.

Figure 6 shows some of the specimens at the end of the test. It is evident that the concrete cover was relatively less damaged in the case of UHPFRC specimens with final failure in compression (Figure 6a) or with rebars failure (Figure 6b) compared with the case of $\mathrm{OC}$ specimen (Figures 6c and 6d). This means that the steel rebars are better protected 


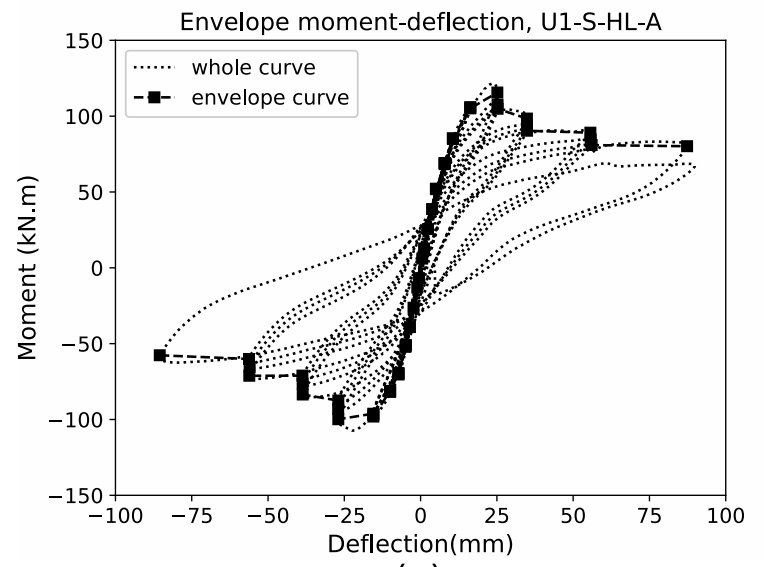

(a)

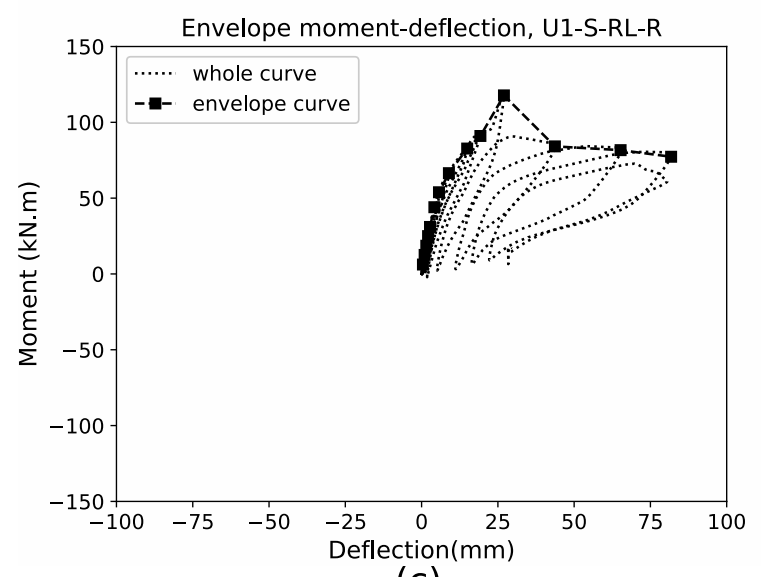

(c)

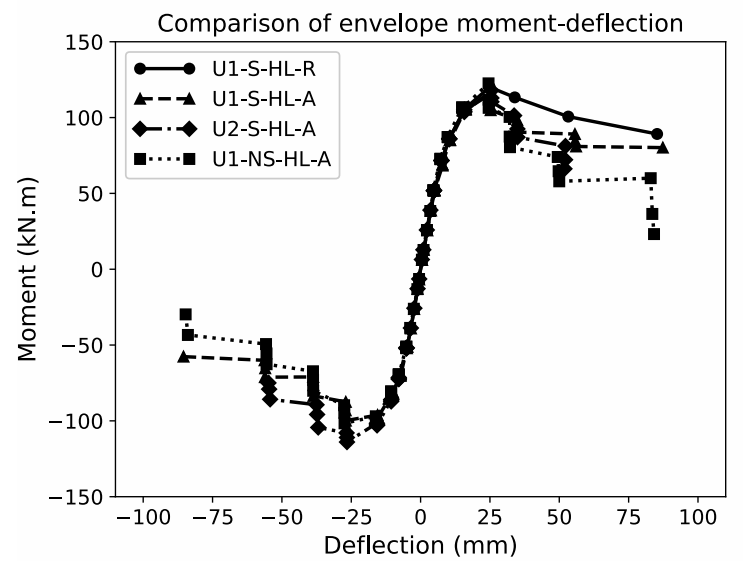

(e)

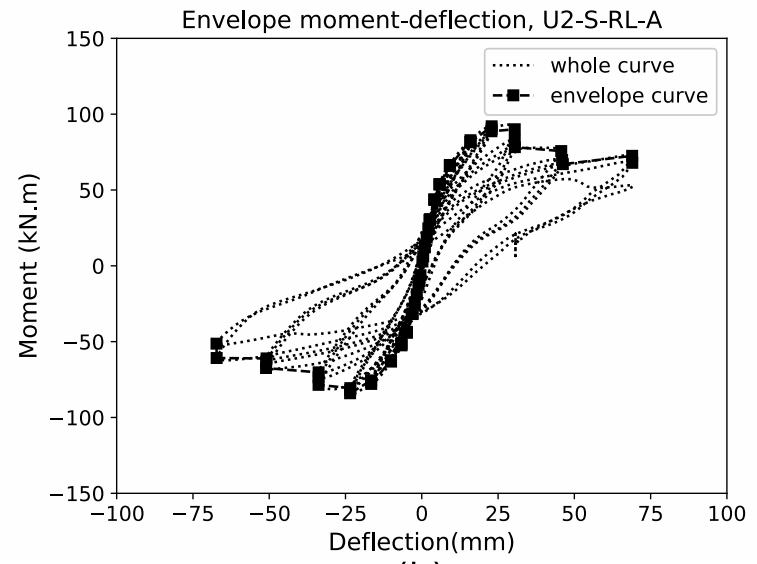

(b)

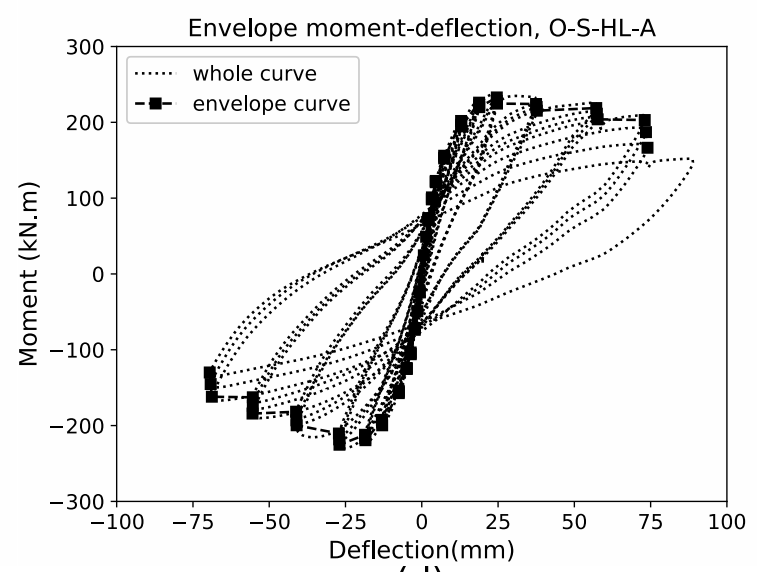

(d)

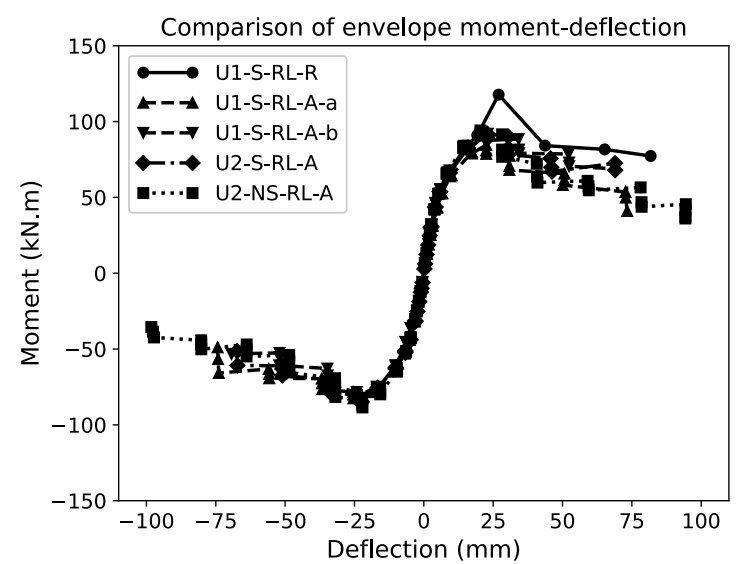

(f)

Figure 5. Envelope bending moment of : (a) U1-S-HL-A; (b) U2-S-RL-A; (c) U1S-RL-R; (d) O-S-HL-A (with a different y-scale as the bending moment is higher). Comparison of envelope bending moment for UHPFRC specimens: (e) tested with a high axial load; (f) tested with a reduced axial load 
Table 4. Main results

\begin{tabular}{|c|c|c|c|c|c|}
\hline \multirow[b]{2}{*}{ Specimen } & \multicolumn{3}{|c|}{ Bending moment } & \multirow{2}{*}{$\begin{array}{c}\text { Failure } \\
\text { mechanism }\end{array}$} & \multirow[t]{2}{*}{ d-fail $^{a}$} \\
\hline & $\min$ & $\max$ & theor. value & & \\
\hline U1-S-HL-R & - & $124.1 k N . m$ & $132 k N . m$ & $?^{b}$ & $\approx 7 \mathrm{~cm}$ \\
\hline U1-S-HL-A & $-107.3 k N . m$ & 121.5 kN.m & $132 k N . m$ & $?^{b}$ & $\approx 9 \mathrm{~cm}$ \\
\hline U2-S-HL-A & $-117.4 k N . m$ & $121.1 \mathrm{kN} . \mathrm{m}$ & $134 k N . m$ & compression & $\approx 0 \mathrm{~cm}$ \\
\hline U1-NS-HL-A & $-112.9 k N . m$ & 128.0 kN.m & $132 k N . m$ & compression & $\in[0,9] \mathrm{cm}$ \\
\hline U1-S-RL-R & - & $\geq 91 k N . m$ & $96 k N . m$ & rebar failure & $\approx 9 \mathrm{~cm}$ \\
\hline U1-S-RL-A-a & $-83.3 k N . m$ & $85.0 \mathrm{kN} . \mathrm{m}$ & $96 k N . m$ & rebar failure & $\approx 6 \mathrm{~cm}$ \\
\hline U1-S-RL-A-b & $-83.5 k N . m$ & 93.3 kN.m & $96 k N . m$ & rebar failure & $\approx 9 \mathrm{~cm}$ \\
\hline U2-S-RL-A & $-84.7 k N . m$ & 93.2 kN.m & $97 k N . m$ & compression & $\approx 9 \mathrm{~cm}$ \\
\hline U2-NS-RL-A & $-89.1 k N . m$ & 96.7 kN.m & $97 k N . m$ & rebar failure & $\approx 0 \mathrm{~cm}$ \\
\hline O-S-HL-A & $-230.2 k N . m$ & $238.3 k N . m$ & $221 k N . m$ & $\Delta h$ & \\
\hline
\end{tabular}

${ }^{a}$ distance between final crack and junction between footing and column

${ }^{b}$ test was stopped before failure

from buckling in the case of UHPFRC specimens than in the case of the OC specimen. Concerning this latter specimen, a certain assymetry in the bending moment-deflection curve can be noted in Figure 5d. This assymetry certainly comes from the fact that, because the column was tested in horizontal position, the loss of concrete around the bottom rebars was more significant than around the top rebars. The bottom rebars were hence more subjected to buckling.

The calculated bending moment values were estimated with the method based on the possible strain distributions at the ultimate limit state described in part 6.1 of (AFNOR 2005a) for the ordinary concrete specimen (O-S-HL-A) and on the corresponding method detailed in (AFGC 2013) and (AFNOR 2016a) for UHPFRC specimens. Interaction diagrams were obtained for each axial load and material used. These diagrams gave the axial force and bending moment limiting values for

- A: reinforcing steel tensile strain limit,

- B: concrete compressive strain limit,

- C: concrete compressive strain limit in case of a cross-section fully under compression (and with uniform compression). 


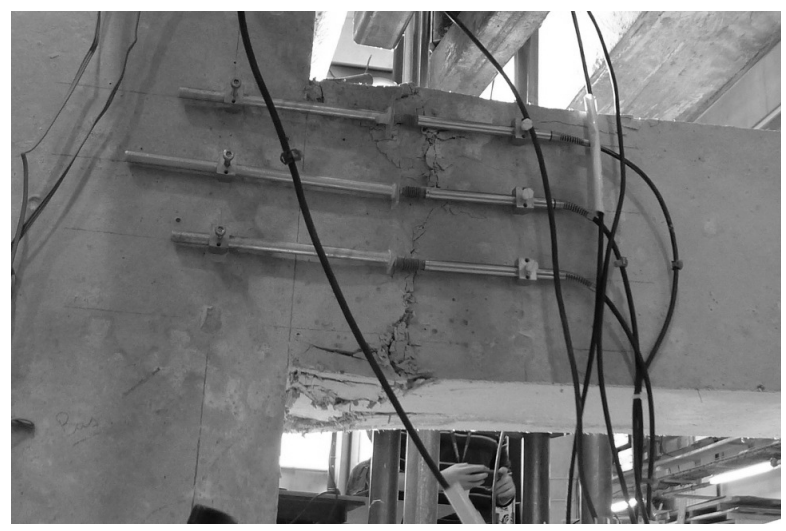

(a)

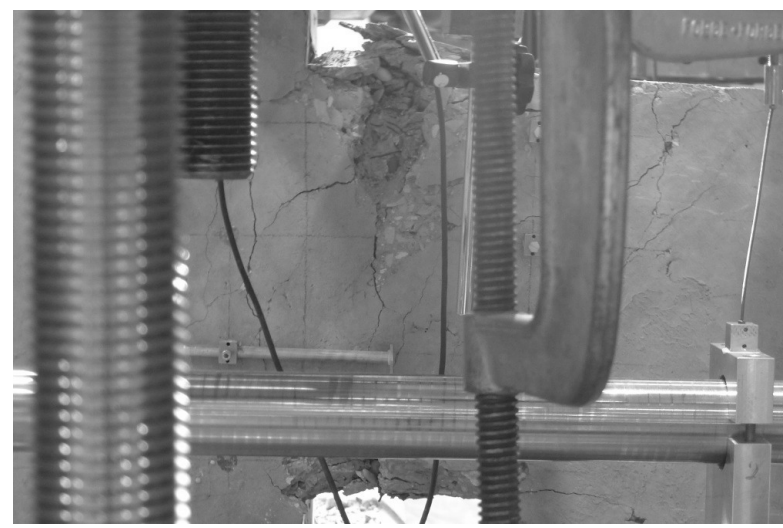

(c)

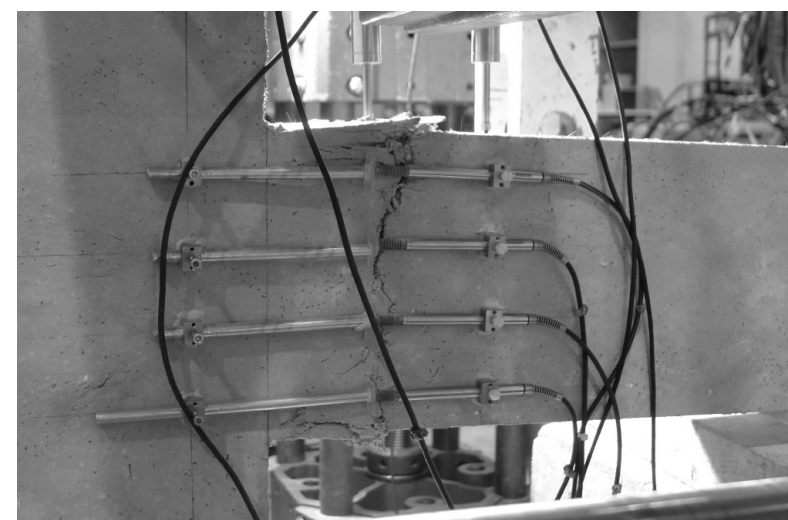

(b)

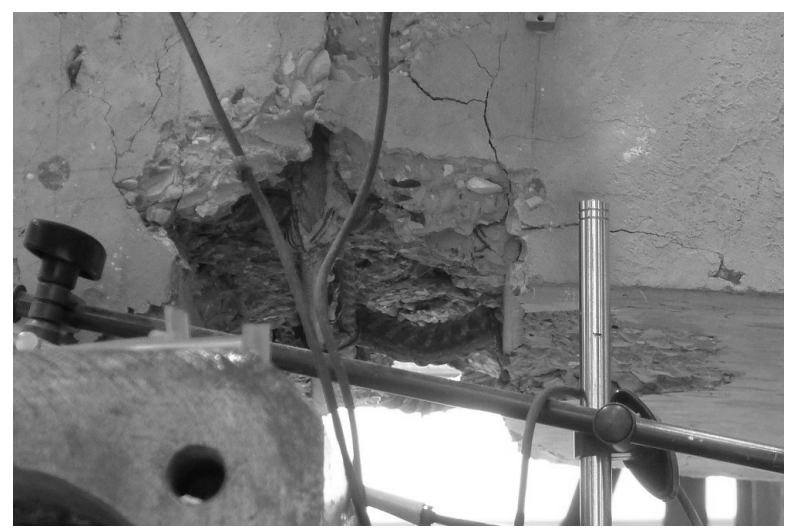

(d)

Figure 6. Specimens at end of test : (a) U1-NS-HL-A before compressive crushing failure; (b) U1-S-RL-A-b before rebars failure; (c) and (d): OC-HL-S-A at end of test

Materials constitutive law used to obtain the maximum bending moments and interaction diagrams

For UHPFRC, the constitutive law has the shape described by Figure 7a. The determination of compressive strains $\epsilon_{c 0}$ and $\epsilon_{c u}$ is based on (AFNOR 2016a), clause 3.1.7.2(1):

$$
\begin{gathered}
\epsilon_{c 0}=\frac{f_{c m}}{E_{c m}} \\
\epsilon_{c u}=\left(1+14 \frac{\sigma(w=0.3 \mathrm{~mm})}{f_{c m}}\right) \cdot \epsilon_{c 0}
\end{gathered}
$$

Using the material characteristic values given by Table 1, we find :

- for UHPFRC1: $\epsilon_{c 0}=3.5210^{-3}$ and $\epsilon_{c u}=6.7210^{-3}$ 


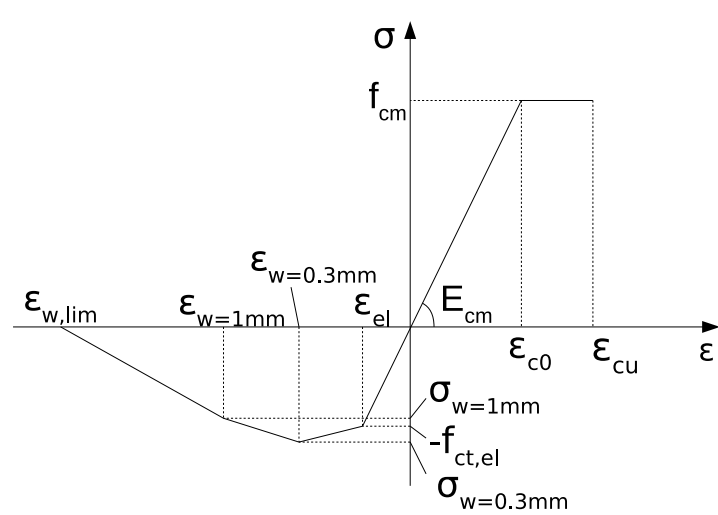

(a)

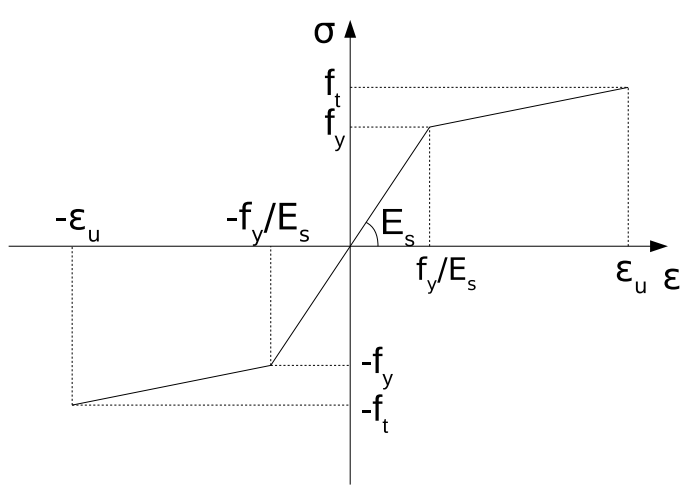

(c)

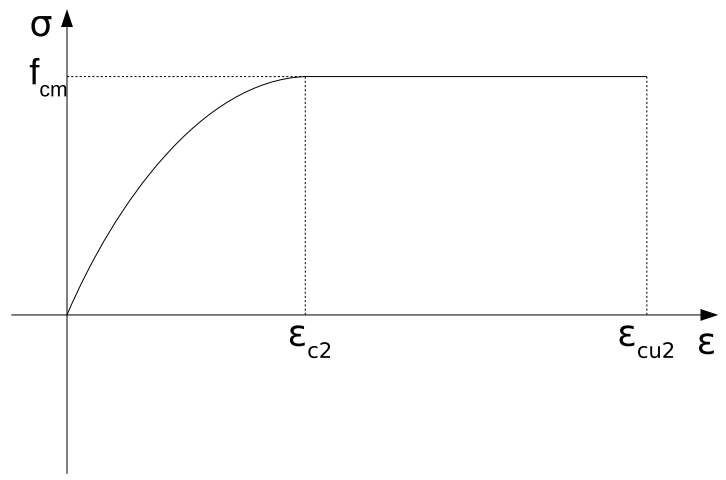

(b)

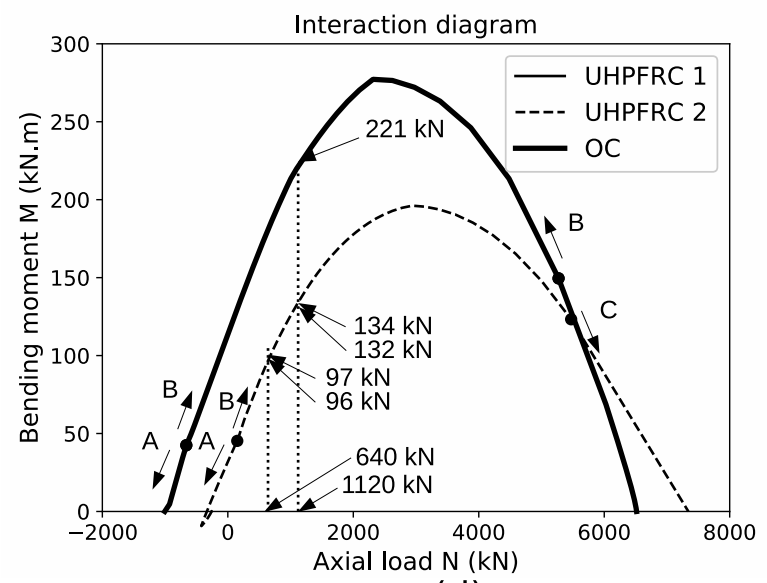

(d)

Figure 7. Shape of the simplified constitutive law used : (a) for UHPFRC ((AFGC 2013) and (AFNOR 2016a)), (b) for ordinary concrete ((AFNOR 2005a)), (c) for steel rebars ((AFNOR 2005a)). (d) Interaction diagram for the column cross-sections of the different specimens

- for UHPFRC2: $\epsilon_{c 0}=3.5710^{-3}$ and $\epsilon_{c u}=7.0210^{-3}$

The tensile post-cracking constitutive law is converted from sigma-crack width law $(\sigma-w)$ into sigma-strain $(\sigma-\epsilon)$ law using the following relation:

$$
\epsilon=-\frac{w}{L_{c}}-\frac{f_{c t m, e l}}{E_{c m}}
$$

where :

- w: the crack width; 
- $L_{c}$, the characteristic length $\left(L_{C}=2 / 3 h\right.$ with $h$ the section depth, $0.2 m$ in our case) ((AFGC 2013) and (AFNOR 2016a));

- $f_{c t m, e l}$, the limit of elasticity, given in Table 1 for each material;

- $E_{c m}$, the mean E-modulus, also given in Table 1 for each material.

The value of $w_{\text {lim }}$ is equal to $\frac{1}{4} L_{f}$, that is $w_{\text {lim }}=5 \mathrm{~mm}$ in our case.

Using the material characteristic values from Table 1, we find:

- for UHPFRC 1: $\epsilon_{e l}=-0.2210^{-3}, \epsilon_{w=0.3 \mathrm{~mm}}=-2.4710^{-3}, \epsilon_{w=1 \mathrm{~mm}}=-7.7210^{-3}$, $\epsilon_{w, l i m}=-37.7210^{-3}$.

- for UHPFRC 2: $\epsilon_{e l}=-0.2310^{-3}, \epsilon_{w=0.3 \mathrm{~mm}}=-2.4810^{-3}, \epsilon_{w=1 \mathrm{~mm}}=-7.7310^{-3}$, $\epsilon_{w, l i m}=-37.7310^{-3}$.

For ordinary concrete, we used a parabola-rectangle constitutive law as shown in Figure 7b. According to (AFNOR 2005a), $\epsilon_{c 2}=2 \cdot 10^{-3}$ and $\epsilon_{c u}=3.510^{-3}$ since the mean compressive strength $f_{c m}$ and consequently its characteristic value $f_{c k}$ are lower than $50 \mathrm{MPa}$.

For rebars, an elasto-plastic constitutive law with an inclined top branch according to (AFNOR 2005a) was used, as shown in Figure 7c. Values of $f_{y}$ and $f_{t}$ are taken equal to $524 \mathrm{MPa}$ and $584 \mathrm{MPa}$ respectively for $12 \mathrm{~mm}$ diameter rebars and $534 \mathrm{MPa}$ and $625 \mathrm{MPa}$ for $16 \mathrm{~mm}$ diameter rebars. For both types of bars, $E_{S}=200 \mathrm{GPa}$ and $\epsilon_{u}=0.06$.

\section{Comparison between experimental and theoretical bearing capacity}

For the OC specimen, the experimentally obtained maximum bending moment and its theoretical value were very close. Conversely, the values from tests were significantly lower (roughly 10\% lower) than the theoretical values for UHPFRC specimens. A highly probable explanation consists in a non optimal fiber orientation at the junction between the footing and the column. Indeed, no fiber orientation factor was considered in the computation, and the UHPFRC laws that were used are those obtained on moulded prisms. Another explanation would be a loss of fiber efficiency during the load cycles; the fibers were submitted alternatively to tension when the cracks were opened under local tensile load, and compres- 
sion when the cracks were closed under local compressive load, which can generate possible buckling of the fibers. These alternate loading cycles possibly accelerate the failure or the pull-out of the fibers.

Concerning the failure mechanisms, most of UHPFRC specimens tested with a high axial load failed in compression and most of UHPFRC specimens tested with a low axial load experienced rebar failure. However, the interaction diagram (figure 7d) shows that theoretically, the strain limit reached was the "B" strain limit, which is the concrete compressive strain limit (UHPFRC crushing). However, one has to consider that the limit between the A strain limit and B strain limit strongly depends on the ultimate tensile strain chosen. Here $\epsilon_{u}$ was taken as the maximum strain value of the rebars determined by characterization tests (mean value) but this value is relatively scattered. Another possible explanation is that the UHPFRC post-cracking tensile strength is lower in the case of alternate loading (compression and tension) than in the characterization tests, which transfers the tensile load on the rebars, generating a rebar failure rather than a compression failure. This would be consistent with the fact that the maximum bending moment observed was lower than the theoretical one.

\section{Energy dissipation}

The energy dissipation due to flexural loading was estimated using the load-deflection $F-\delta$ curve, with $F$ the vertical force applied by the jack, and $\delta$ the vertical displacement. The method consists in integrating the $F-\delta$ curve for each half cycle as shown in Figure $8 \mathrm{a}$ in the case of alternate loading protocol and in Figure 8b in the case of repeated loading protocol.

Figures $8 \mathrm{c}, 8 \mathrm{~d}$ and $8 \mathrm{e}$ show the energy dissipation at each half load cycle, respectively, for UHPFRC specimens tested with a high axial load (HL), for UHPFRC specimens tested with a reduced axial load (RL) and for the OC specimen. The dissipated energy is represented as a function of the extreme displacement value observed during the half cycle. Figures $8 \mathrm{c}$ and $8 \mathrm{~d}$ show that for UHPFRC specimens, the dissipated energy is quite the same whatever the 


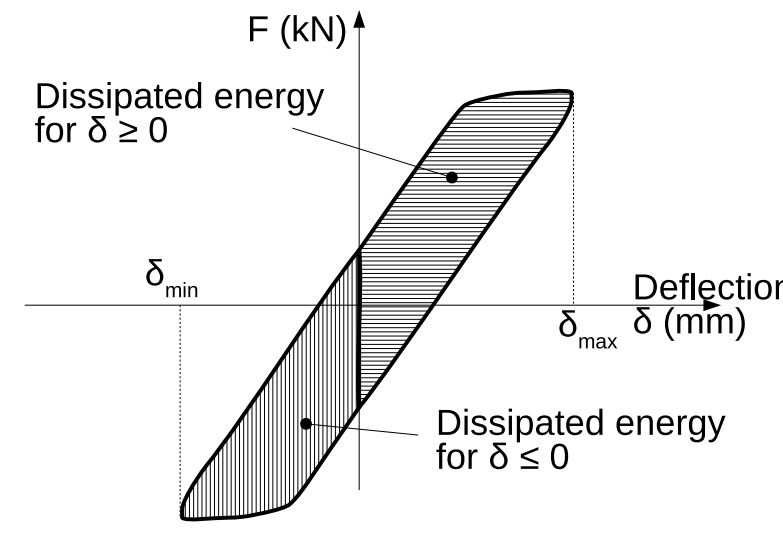

(a)

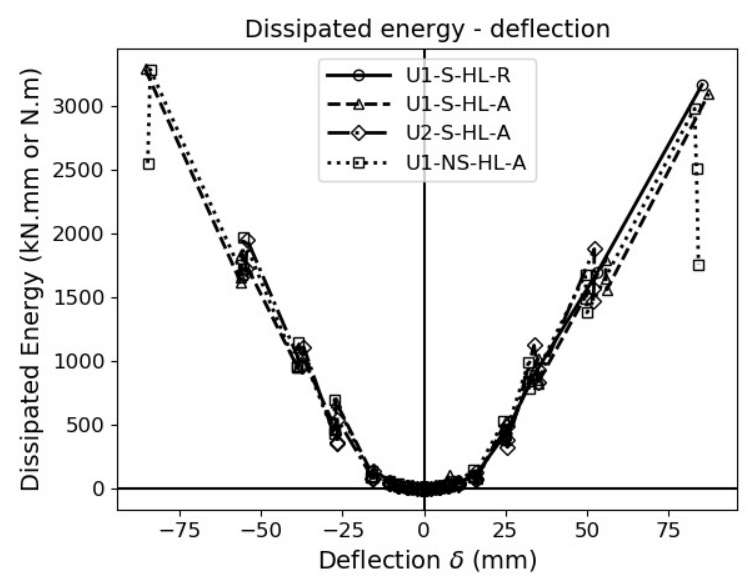

(c)

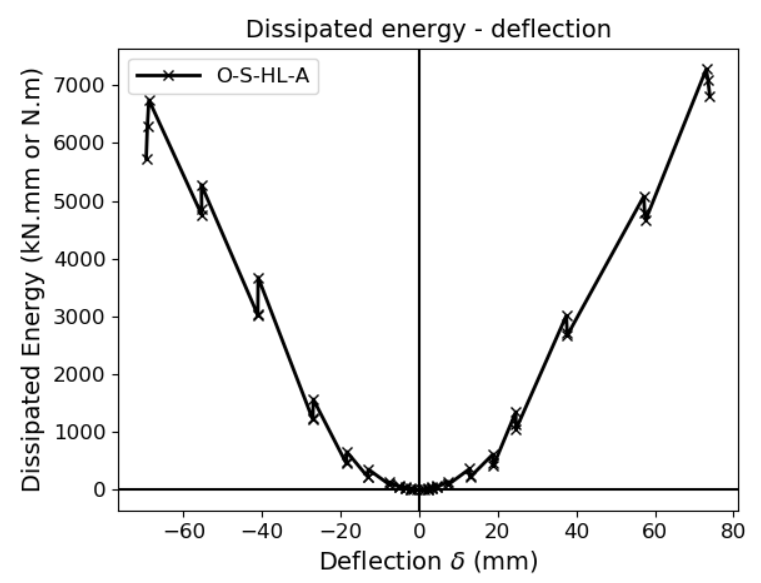

(e)

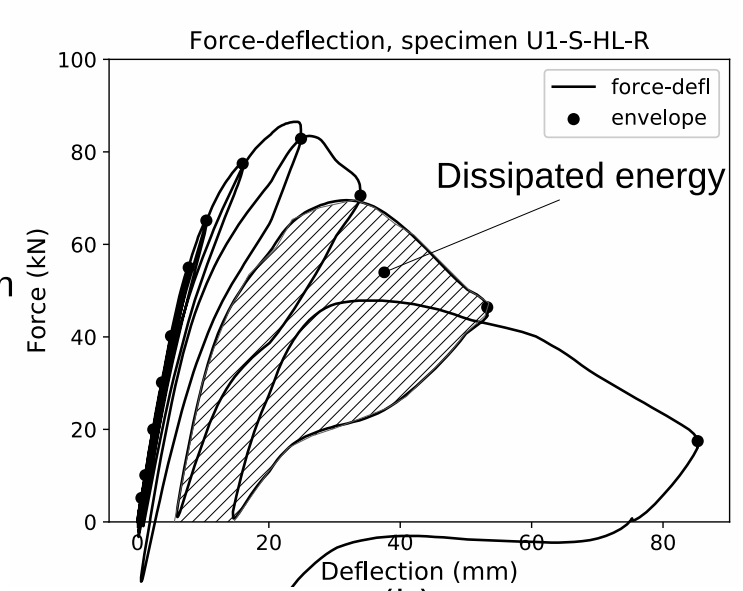

(b)

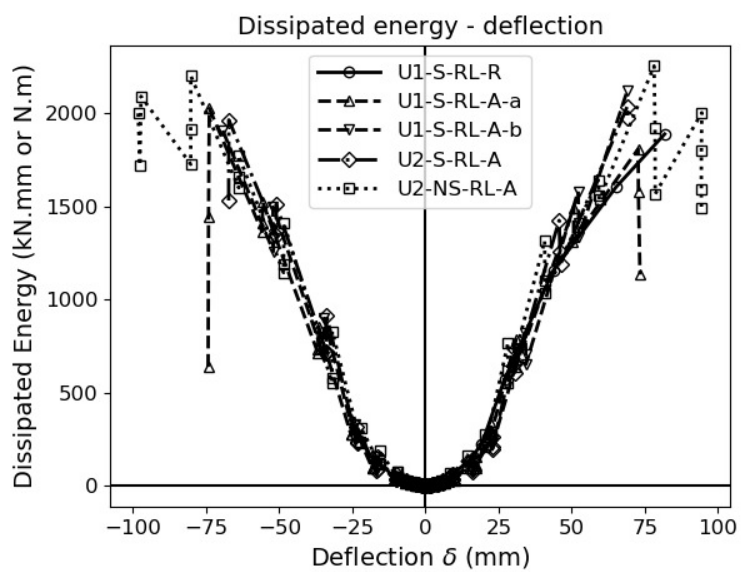

(d)

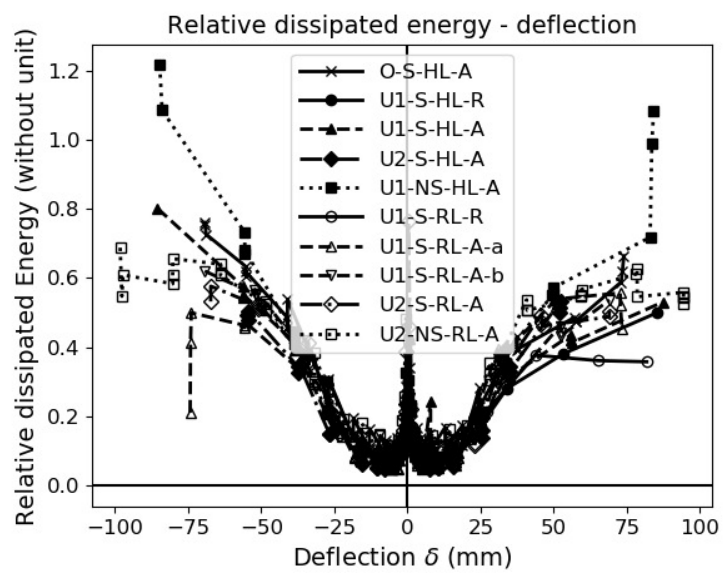

(f)

Figure 8. Energy dissipation during load cycles : (a) method used to determine energy dissipation for alternate loading; (b) method used to determine energy dissipation for repeated loading; (c) dissipated energy for UHPFRC specimens tested with a high axial load; (d) dissipated energy for UHPFRC specimens tested with a reduced axial load; (e) dissipated energy for OC specimen; (f) relative dissipated energy for all specimens. 
kind of specimen (with or without shear reinforcement) and whatever the loading protocol (repeated or alternate). The Figure 8e shows the dissipated energy for the OC specimen. For this latter specimen, the dissipated energy was higher, which is consistent with the fact that the specimen develops a higher bending moment.

In order to compare the specimens properly, the relative dissipated energy $E_{\text {relative-dissip }}$ was calculated as follows (eq. 5):

$$
E_{\text {relative-dissip }}=\frac{E_{\text {dissip }}}{\delta_{\max } \times \operatorname{force}\left(\delta_{\max }\right)}
$$

where:

- $E_{\text {dissip }}$ : the dissipated energy during the half cycle

- $\delta_{\max }$ : the extreme displacement (maximum if displacement is positive, minimum otherwise) during the half cycle considered

- $\operatorname{force}\left(\delta_{\max }\right)$ : the vertical force observed for $\delta_{\max }$

This enables comparing the energy dissipated for every specimen with a dimensionless energy.

The relative dissipated energy is shown on Figure 8f. It appears that the capacity of dissipation was quite the same for UHPFRC and for OC specimens whatever the axial load.

\section{Ductility}

To evaluate the ductility of the different specimens submitted to alternate load protocol, three displacement parameters have been determined and compared, as shown in Figures 9a and $9 \mathrm{~b}$ :

- $\Delta_{y}$ yield displacement value, equal to $\left(\left|+\delta_{y}\right|+\left|-\delta_{y}\right|\right) / 2$

- $+\delta_{y}$ and $-\delta_{y}$ are the intersections of the tangent at origin with the envelope curves of respectively the maximum moment values and the minimum moment values of the cycles, respectively; 


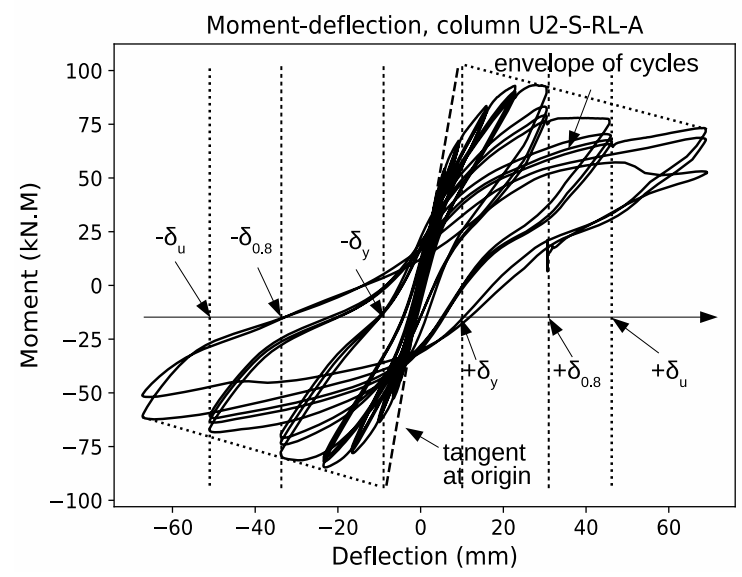

(a)

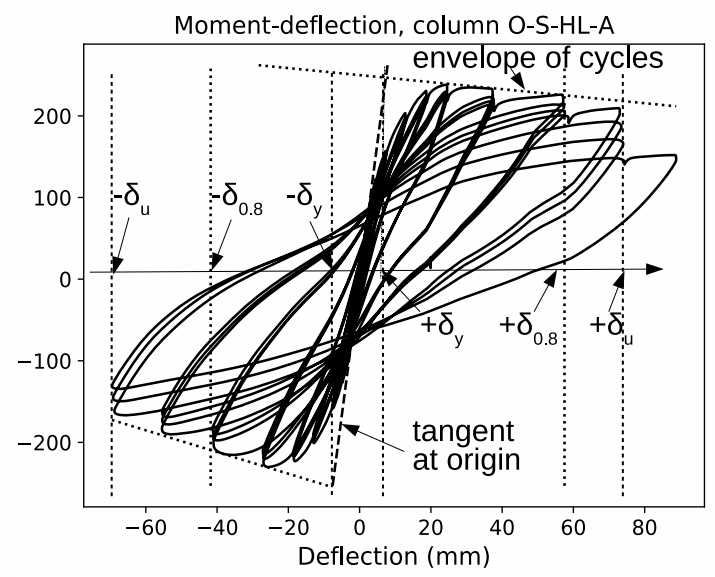

(b)

Figure 9. Obtaining ductility parameters for: (a) UHPFRC specimen U2-S-RL-A; (b) ordinary concrete specimen $\mathrm{O}-\mathrm{S}-\mathrm{HL}-\mathrm{A}$.

Table 5. Ductility parameters

\begin{tabular}{ccccccccc}
\hline Specimen & $\begin{array}{c}\left(+\delta_{y},-\delta_{y}\right) \\
(\mathbf{m m}, \mathbf{m m})\end{array}$ & $\begin{array}{c}\Delta_{y} \\
\mathbf{m m}\end{array}$ & $\begin{array}{c}\left(+\delta_{0.8},-\delta_{0.8}\right) \\
(\mathbf{m m}, \mathbf{m m})\end{array}$ & $\begin{array}{c}\Delta_{0.8} \\
\mathbf{m m}\end{array}$ & $\lambda_{0.8}$ & $\begin{array}{c}\left(+\delta_{u},-\delta_{u}\right) \\
(\mathbf{m m}, \mathbf{m m})\end{array}$ & $\begin{array}{c}\Delta_{u} \\
\mathbf{m m}\end{array}$ & $\lambda_{u}$ \\
\hline U1-S-HL-A & $(10.5,-9.4)$ & 10.0 & $(25.3,-27.0)$ & 26.2 & 2.6 & $(56.1,-56.2)$ & 56.2 & 5.6 \\
U2-S-HL-A & $(11.0,-11.2)$ & 11.1 & $(25.5,-26.7)$ & 26.1 & 2.4 & $(52.2,-54.8)$ & 53.5 & 4.8 \\
U1-NS-HL-A & $(11.5,-10.3)$ & 10.9 & $(24.5,-27.6)$ & 26.1 & 2.4 & $(50.0,-55.7)$ & 52.9 & 4.9 \\
U1-S-RL-A-a & $(8.9,-8.5)$ & 8.7 & $(22.5,-36.7)$ & 29.6 & 3.4 & $(50.8,-55.8)$ & 53.3 & 6.1 \\
U1-S-RL-A-b & $(9.1,-8.4)$ & 8.7 & $(34.3,-24.1)$ & 29.2 & 3.3 & $(52.4,-52.2)$ & 52.3 & 6.0 \\
U2-S-RL-A & $(9.2,-8.4)$ & 8.8 & $(30.0,-33.8)$ & 31.9 & 3.6 & $(46.2,-51.1)$ & 48.7 & 5.5 \\
U2-NS-RL-A & $(9.0,-8.4)$ & 8.7 & $(20.4,-22.3)$ & 21.4 & 2.4 & $(59.7,-64.0)$ & 61.9 & 7.1 \\
O-S-HL-A & $(7.4,-7.6)$ & 7.5 & $(57.5,-41.8)$ & 49.7 & 6.6 & $(74,-69.5)$ & 71.8 & 9.6 \\
\hline
\end{tabular}

- $\Delta_{0.8}$ maximum displacement value corresponding to a bending moment loss lower than $20 \%$, equal to $\left(\left|+\delta_{0.8}\right|+\left|-\delta_{0.8}\right|\right) / 2$

- $+\delta_{0.8}$ is the maximum displacement value of series of three cycles for which the maximum moment value of each cycle remains higher than $80 \%$ of the global maximum moment values of the whole moment-displacement curve.

- $-\delta_{0.8}$ is the minimum displacement value of series of three cycles for which the minimimum moment value of each cycle remains lower than $80 \%$ of the global minimimum moment values of the whole moment-displacement curve; 
- $\Delta_{u}$ ultimate displacement value, to $\left(\left|+\delta_{u}\right|+\left|-\delta_{u}\right|\right) / 2$

- $+\delta_{u}$, the maximum displacement value reached by series of three cycles without failure.

- $-\delta_{u}$, the minimum displacement value reached by series of three cycles without failure.

Coefficients $\lambda_{0.8}\left(\right.$ resp. $\left.\lambda_{u}\right)$ are calculated as the ratio between $\Delta_{0.8}\left(\right.$ resp. $\left.\Delta_{u}\right)$ and $\Delta_{y}$ :

$$
\begin{gathered}
\lambda_{0.8}=\Delta_{0.8} / \Delta_{y} \\
\lambda_{u}=\Delta_{u} / \Delta_{y}
\end{gathered}
$$

Table 5 gives the numerical values of these parameters for the different tested specimens.

Coefficient $\lambda_{0.8}$ gives an indication about the ability of the specimen to accept large displacements and maintain a high bending moment during the load cycles. It was inspired by the criterion proposed by annex U of (AFNOR 2016a), even if this document suggests taking into account series of 5 cycles instead of 3 cycles as done here. It is called the "ductility coefficient" hereafter.

Coefficient $\lambda_{u}$ gives an indication about the ability of the specimen to accept large displacement during the load cycles without failure.

The ductility coefficient $\lambda_{0.8}$ enables seeing that the ductility is better for the UHPFRC specimens tested with a reduced axial load compared to those tested with a high axial load. Furthermore, the shear reinforcement seems to have a positive effect in the case of reduced axial loads. Its effect was more questionable in the case of UHPFRC specimens tested with a high axial load. Moreover, even if the ductility appeared to be much better in the case of the ordinary reinforced concrete according to (AFNOR 2005b), the ductility of UHPFRC specimens simply reinforced with longitudinal rebars and with or without additionnal light transverse reinforcement was not negligible and might be sufficient in cases of low or moderate 
Table 6. Column deflection for different crack widths

\begin{tabular}{|c|c|c|c|c|c|c|}
\hline Specimen & 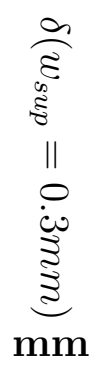 & 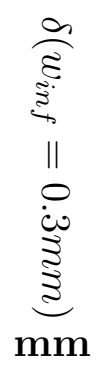 & 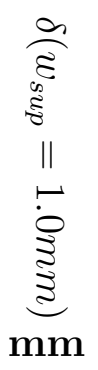 & 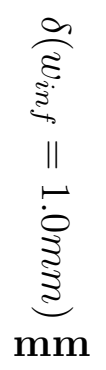 & 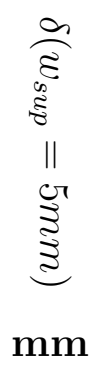 & 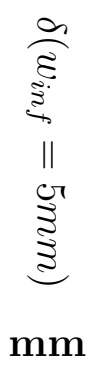 \\
\hline U1-S-HL-R & 11.7 & $-{ }^{a}$ & 21.4 & $-^{a}$ & 47.7 & $-{ }^{a}$ \\
\hline U1-S-HL-A & 11.5 & -11.0 & 21.3 & -20.6 & 45.7 & $-b$ \\
\hline U2-S-HL-A & 10.7 & -11.3 & 20.5 & -20.2 & $-b$ & $-b$ \\
\hline U1-NS-HL-A & 10.6 & -11.1 & 21.6 & -21.9 & $-b$ & $-b$ \\
\hline U1-S-RL-R & 9.8 & ${ }^{a} a$ & 18.1 & $-a$ & 44.2 & $-^{a}$ \\
\hline U1-S-RL-A-a & 9.4 & -8.9 & 20.0 & -19.1 & 43.5 & -46.3 \\
\hline U1-S-RL-A-b & 8.1 & -8.1 & 17.6 & -18.3 & 44.4 & -45.9 \\
\hline U2-S-RL-A & 9.4 & -9.3 & 19.8 & -19.4 & 41.6 & -43.3 \\
\hline U2-NS-RL-A & 7.8 & -8.4 & 17.5 & -18.6 & 40.6 & -47.8 \\
\hline
\end{tabular}

${ }^{a}$ only upper chord was under tension for repeated load protocol

${ }^{b}$ at least one extensometer fell before $\mathrm{w}$ reached $5 \mathrm{~mm}$

seismicity (AFNOR 2005b).

The coefficient $\lambda_{u}$ enables to see that the UHPFRC specimens can continue sustaining the axial load for large vertical displacements even if the bending moment is substantially reduced. This reduction is mainly due to the loss of fibers efficiency at the junction between the column shaft and the footing during the alternate cycles, because the specimens have been cast at one time (without construction joint generating an interruption of fibers).

\section{Crack width}

Crack widths have been assessed with the four $20 \mathrm{~cm}$ long extensometers placed at the junction between footing and the column shaft (see Figures $6 \mathrm{a}$ and $6 \mathrm{~b}$ ). Because there is a crack localization over the extensometer length, and neglecting the strain on each side of the crack, the crack width can be taken equal to the extensometer displacement. Because the extensometers were placed in the middle of the face, a linear regression was performed to extrapolate the extensometer displacements on the upper and the lower chord. 
Table 6 shows the column deflection corresponding to crack widths of $0.3,1.0$ and $5 \mathrm{~mm}$ on the upper and lower chord in the vicinity of the junction. A crack width of $0.3 \mathrm{~mm}$ corresponds approximately to the maximal tensile stress of the UHPFRC while $5 \mathrm{~mm}$ corresponds to a tensile stress of the UHPFRC close to zero (fibers are pulled out, only rebars take the tensile force).

Noticeably enough, the results concerning the crack widths show a good repeatibility whatever the kind of loading procedure (repeated or alternate). The crack width of $0.3 \mathrm{~mm}$ was reached roughly for $\delta_{y}$ (before the peak load). A crack width of $1.0 \mathrm{~mm}$ was obtained for a deflection value between $\delta_{y}$ and $\delta_{0.8}$ that was close to the peak load. A crack width of $5 \mathrm{~mm}$ is obtained between $\delta_{0.8}$ and $\delta_{u}$ which shows that only rebars were taking the tensile load at $\delta_{u}$.

\section{DISCUSSION}

For UHPFRC, the maximum bending moment was roughly the same whatever the kind of loading protocol (repeated or alternate). This means that the UHPFRC tensile behaviour was hardly affected by the alternate loading at least for moderate crack widths (leading to the maximum bending moment). For larger crack widths (once the maximum bending moment has been reached), the effect of alternate loading was more important. Once cracks were sufficiently opened, fibers tended to buckle under the effects of compression which limit their efficiency when these fibers are subjected to tension again.

Although it was observed that shear reinforcement seems to play a positive role for ductility (see values of $\lambda_{0.8}$ in Table 5 or Figure 5e) shear reinforcement can also have a negative effect on the fiber orientation, which can induce cracking. For almost all the UHPFRC specimens with shear reinforcement, cracks and failure have occured a few centimeters beyond the junction between the footing and the column shaft (in the vicinity of the first stirrup of the column) and not at the junction itself as is generally the case when no shear reinforcement is used. This also explains why the maximum bending moment is a bit higher for specimens with no shear reinforcement. 
It has been shown that UHPFRC specimens can sustain the axial load even for very important transversal displacements, but with a reduced bending moment. This decrease is mainly due to the loss of fiber efficiency under alternate loading. Nevertheless, even if it experienced cracking, the UHPFRC appeared hardly damaged under the alternance of transversal load, which enables limiting the decrease of the lever arm of the section's internal forces. For a better ductility, it could be useful to test such specimens but with no fibers in at least one section in the vicinity of the junction of the footing and the column shaft, as is the case in (Palacios et al. 2015). Indeed, there would be less decrease of bending moment capacity since fibers would only help to maintain integrity of the section without participating in taking the bending moment. The other possibilities to improve the ductility would be to use more ductile steel rebars, to increase the hinge length with notches in the UHPFRC cover to develop several cracks and/or to create a zone without bond between the rebars and the concrete at the junction, as proposed by (Tazarv and Saiid Saiidi 2014).

The ductility shown by the specimens tested in our program is nevertheless far from being negligible because the minimum value of ductility coefficient $\lambda_{0.8}$ was 2.4 as can be seen in table 5 .

The relative energy dissipation of UHPFRC specimens was also comparable with the energy dissipation of the ordinary concrete specimen, which shows that even if the anchorage

length of steel rebars is much lower in the case of UHPFRC (see (Marchand et al. 2015)), a reasonable minimum ability to dissipate energy is kept for UHPFRC.

\section{CONCLUSIONS}

The tests carried out have thus shown that:

- UHPFRC specimens with a longitudinal reinforcement and a slight shear reinforcement display a satisfactory minimum ductility, so that a ductility coefficient a bit higher than 2 can be used for such structures;

- UHPFRC specimens dissipate energy simililarly to the ordinary concrete specimen; 
- the type of test protocol (alternate or repeated) has a very limited influence on the maximum bending moment observed;

- the influence of moderate shear reinforcement can be negative on the maximum bending moment but is positive in terms of ductility.

\section{ACKNOWLEDGEMENTS}

Most of the graphs displayed in this article have been plotted with the Matplotlib Library ((Hunter 2007)) of Python programming language.

The works detailed in this paper were carried out within BADIFOPS research project, aiming at developing ductile solutions of UHPFRC structures for earthquake-resistant applications, where optical fibers SHM can be fruitfully applied. BADIFOPS is a French-State sponsored project (2011-2014) within "Design and Build for Sustainable Growth" program of the Civil Engineering Department Unit of the Ministry in charge of Sustainable Growth (grant $\mathrm{n}^{\circ} 10$ MGC S010). Partners are Eiffage Company, CSTB (research center for buildings), Ifsttar (public works research institute) and Sétra, now CEREMA (Highways Agency). The authors declare that they have no conflict of interest. 


\section{Appendix I. References}

AFGC (2013). "Ultra high performance fibre-reinforced concretes." Recommendations, AFGC, Paris, France, 357 pages.

AFNOR (2005a). "Eurocode 2: Design of concrete structures - part 1-1: General rules and rules for buildings." NF EN 1992-1-1, AFNOR, La Plaine Saint-Denis, France, 225 pages.

AFNOR (2005b). "Eurocode 8 - design of structures for earthquake resistance - part 1 : general rules, seismic actions and rules for buildings." NF EN 1998-1, AFNOR, La Plaine Saint-Denis, France, 229 pages.

AFNOR (2010). "European standard - steel for the reinforcement and prestressing of concrete

- test methods - part 1 : reinforcing bars, wire rod and wire." NF EN 15630-1, AFNOR, La Plaine Saint-Denis, France.

AFNOR (2013). "French standard, admixtures - curing products for concrete and mortar - definition, specifications and marking." NF P 18-3\%0, AFNOR, La Plaine Saint-Denis, France, 11 pages.

AFNOR (2016a). "French standard, national addition to eurocode 2 - design of concrete structures: specific rules for ultra-high performance fibre-reinforced concrete (UHPFRC)." NF P 18-710, AFNOR, La Plaine Saint-Denis, France, 136 pages.

AFNOR (2016b). "French standard, ultra-high performance fibre-reinforced concrete: Specifications, performance, production and conformity." NF P 18-470, AFNOR, La Plaine Saint-Denis, France, 94 pages.

Behloul, M. (1996). "Analyse et modélisation du comportement d'un matériau à matrice cimentaire fibrée à ultra hautes performances." Ph.D. thesis, E.N.S. Cachan, Cachan, France.

CEREMA (2015). Ponts en zone sismique, conception et dimensionnement selon l'Eurocode 8, Bridges in seismic zone, design according to Eurocode 8. CEREMA-DTecITM, Provins France.

Chanvillard, G. and Rigaud, S. (2003). "Complete characterization of tensile properties of 
Ductal@ UHPFRC according to the French recommendations." Proc., 4th Int. RILEM Workshop (UHPFRCC4)., RILEM, 21-34.

Dutalloir, F., Thibaux, T., Cadoret, G., and Birelli, G. (1998). "Un nouveau béton très hautes performances : le BSI - première application industrielle / B.S.I. : A new, very high performance concrete. initial industrial application." Proc., 13th FIB Congress, Amsterdam., La technique française du béton, ed., RILEM, AFPC-AFREM, 25-32.

Federal Highway Administration (FHWA) (2014). LRFD Seismic Analysis and Design of Bridges, Reference Manual. Publication No. FHWA-NHI-15-004, Washington, D.C.

Frettlöhr, B., Corvez, D., Chatoux, E., and Reineck, K. H. (2012). "Tests on the flexural tensile strength of a uhpfrc subjected to cycling and reversed loading." HiperMat, Kassel, $427-433$.

Graybeal, B. (2011). "Ultra-high performance concrete." Report No. FHWA-HRT-11-038, U.S. Department of Transportation, Federal Highway Administration.

Hunter, J. D. (2007). "Matplotlib: A 2d graphics environment." Computing In Science 8 Engineering, 9, 90-95.

Ichikawa, S., Matsuzaki, H., Moustafa, A., El Gawady, M. A., and Kawashima, K. (2016). "Seismic-resistant bridge columns with ultrahigh-performance concrete segments." Journal of Bridge Engineering, 21(9).

Marchand, P., Baby, F., Khadour, A., Battesti, T., Rivillon, P., Quiertant, M., Nguyen, H. H., Généreux, G., Deveaud, J. P., Simon, A., and Toutlemonde, F. (2015). "Bond behaviour of reinforcing bars in uhpfrc, experimental investigation." Materials and Structure, 49(5), 1979-1995.

Massicotte, B. and Boucher-Proulx, G. (2011). "Seismic retrofitting of bridge piers with uhpfrc jackets." Designing and Building with UHPFRC, state of the Art and Development, ISTE, ed., AFGC, Marseille, France, 531-540.

Naaman, A. E. and Reinhardt, H. W. (1996). "Characterization of high performance fiber reinforced cement composites - hpfrcc." High Performance Fiber Reinforced Cement Com- 
posites 2, A. E. Naaman and H. W. Reinhardt, eds., London, England, E\&FN Spon, 1-24. Palacios, G., Chao, S. H., Novajan, A., and Schultz, A. (2015). "Performance of full-scale ultra high performance fiber-reinforced concrete (UHP-FRC) column subjected to extreme earthquake-type loading." High Performance Fiber Reinforced Cement Composites (HPFRCC 7), Stuttgart, Germany, 401-408.

Richard, P. and Cheyrezy, M. (1995). "Composition of reactive powder concretes." Cement and Concrete Research, 25(7), 1501-1511.

Sogabe, N., Yamanobe, S., and Kono, T. (2008). "Cyclic loading test of high-seismicperformance RC piers with ultra-high-strength fiber-reinforced concrete precast forms." $H S C-H P C$, Tokyo, Japan.

Spasojević, A. (2008). "Structural implications of ultra high performance fibre-reinforced concrete in bridge design." Ph.D. thesis, Ecole Polytechnique Fédérale de Lausanne, Lausanne, Switzerland.

Tazarv, M. and Saiid Saiidi, M. (2014). "Next generation of bridge columns for accelerated bridge construction in high seismic zones." Technical report CA14-2176, University of Nevada, Reno, Nevada, USA.

Toutlemonde, F. and Resplendino, J. (2011). Designing and Building with UHPFRC: State of the Art and Development. ISTE-Wiley.

Toutlemonde, F., Simon, A., Rivillon, P., Marchand, P., Baby, F., Quiertant, M., Khadour, A., Cordier, J., and Battesti, T. (2013). "Recent experimental investigations on reinforced UHPFRC for applications in earthquake engineering and retrofitting." UHPFRC 2013 Designing and Building with UHPFRC: from innovation to large-scale realizations, Marseille, France, RILEM pro087, 597-606.

Walraven, J. (2009). "High performance fiber reinforced concrete: Progress in knowledge and design codes." Materials and Structures, 42, 1247-1260. 